\title{
The Effect of BACILLUS SUBTILIS SY1 and PSEUDOMONAS FLURESCENS W1 in the Ecological Remediation of the Soil
}

\author{
Xin Liu (Corresponding author) \\ School of Chemical Engineering, Tianjin University of Science and Technology \\ Mailbox 526 Tianjin University of Science and Technology \\ 1038 Dagunan Road, Hexi district, Tianjin, 300222, China \\ Tel: 50-6-453-3535 E-mail: v089i@unb.ca \\ Jinzhao Pang \\ School of Chemical Engineering, Tianjin University of Science and Technology \\ 1038 Dagunan Road, Tianjin, 300222, China \\ Tel: 86-22-6027-3577 E-mail: jzpang@sina.com \\ Zongzheng Yang \\ School of Chemical Engineering, Tianjin University of Science and Technology \\ 1038 Dagunan Road, Tianjin, 300222, China \\ Tel: 86-22-6027-3577 E-mail: yzz3520@hotmail.com
}

This work was financed by the National Science and Technology Planning Project of China (Grant no. 2006BAD32B07) and Chinese Postdoctoral Science Foundation (Grant no. 20060400708).

\begin{abstract}
As years of unreasonable farming practices in agriculture soil damaged seriously. The soil-borne disease and the chemical residue are two serious problems of soil pollution which affect the yield and quality of agricultural products. Ecological remediation of soil is an effective way to resolve these problems and maintain the sustainable development of agriculture. In this paper the agents Bacillus subtilis SY land Pseudomonas flurescens W1 were used to improve the ecosystem function and reduce the disease occurrence.
\end{abstract}

Keywords: Soil pathogens, Pesticide residue, Ecological remediation, Sustainable development

\section{Introduction}

Due to the excessive use and misuse of chemical pesticides, chemical fertilizers and unreasonable farming practices in modern agriculture, many serious soil environmental problems emerge, especially in facility agriculture, such as soil fertility deterioration, organic chlorine pesticide residue and plant fungal pathogens. To overcome these problems, biological remediation has recently been developed and beneficial agents, such as Bacillus subtilis (Shinji Mizumoto et al, 2007; Wang J et al, 2007; Marc Ongena et al, 2005), and Pseudomonas flurescens (ZHANG et al, 2007; D.C. Naseby et al, 2001, 1998) are widely used.

In the paper Bacillus subtilis SY 1and Pseudomonas flurescens W1 were used in the experiments to determine their bioremediation effect in soil. The eggplant planting experiments indicated that Bacillus subtilis SY1 could improved the function of rhizosphere ecosystems in soil and promote the plant growth and increase stress tolerance. The American ginseng planting experiments showed that the organic chlorine pesticide residue in soil and American ginseng reduced, meanwhile, the functions of rhizosphere ecosystems of soil improved and the growth of American ginseng accelerated accordingly.

\section{Materials and method}

\subsection{Microbial agents}

The Bacillus subtilis SY1 used through this work was preserved in the laboratory. The Pseudomonas flurescens W1 was separated from soil in American ginseng planting base. Four fungi plant pathogens are provided by Vegetable Research Institute, Tianjin Academy of Agriculture Sciences. 


\subsection{Experimental method}

\subsubsection{Eggplant pot experiment}

Eggplant seeds were disinfected with $70 \%$ ethanol -water ratio solution and then with $0.5 \%$ sodium hypochlorite. After rinsing six times with sterile water, the seeds were soaked in the water to pregermination. After three days, eggplant seeds were selected and sown into the pots. The plants were irrigated with water every other day. After 3 and 16 days sowing, $3 \mathrm{~mL}$ Bacillus subtilis SY1 suspension was added as drench to the roots of the plant except the controls (which was only watered with $3 \mathrm{~mL}$ sterilized saline).

After 20 days, the growth situation and antioxygen enzyme of eggplant seedling were determined. After 40 days, the species and population of microorganisms in the soil of inoculated and control were determined by spread-plate method.

In vitro antagonistic examination the antifungal activity of Bacillus subtilis SY1 was tested against the four typical soil-borne pathogen diseases on the PDA media. Spore suspensions with different fungi 5 days old cultures, the concentration was more than $106 \mathrm{cfu} / \mathrm{mL}$ ) have been prepared in $0.85 \%$ sterilized saline. The melted solid wateragar medium was put on the plates, the sterile stainless steel columns were put on the frozen solid agar. When the melted semisolid PDA media cooled to $40-50^{\circ} \mathrm{C}, 1 \mathrm{~mL}$ of spore suspensions of each fungus was put in and well-mixed with PDA media. The mixture was then put onto the wateragar medium plates using transfer pipet. When the agar was frozen solid, the stainless steel columns were taken away and $50 \mu \mathrm{L}$ transformation was put into the hole except the controls (put into $50 \mu \mathrm{L}$ sterilized saline). Every treatment repeated three times. The plates have been incubated at $28 \pm 1^{\circ} \mathrm{C}$ for 7 days to detect the diameter of fungal inhibition around.

\subsubsection{American ginseng field experiment}

The field experiment of inoculated and control were did in the American ginseng planting base. The inoculated and the control were did simultaneously and were both repeated for three times. After disinfecting the ginseng roots were regularly arranged on the land which surface soil was removed in advance. After covering the soil onto ginsengs again 5 $\mathrm{mL}$ Pseudomonas flurescens $W 1$ suspension was added as drench to the roots of the American ginseng. Three times of inoculation were did in the first three month after sowing. The ginsengs and the soil around their roots were dug out after 12 month to be analyzed.

\subsection{Analysis method}

Chlorophyll content_—B By means of ethanol extraction

Superoxide dismutase (SOD)—B — By means of nitroblue tetrazolium photoreduction

Catalase (CAT) — By means of ultraviolet absorption

Peroxidase (POD) —_By means of guaiacol method (Wu et al, 2006)

Total saponins —-By means of thin layer chromatography

BHC and DDT — By means of gas chromatography/microelectron capture detector ( $\mu$-ECD)

\section{Results and discussion}

\subsection{Eggplant pot experiment}

\subsubsection{The microecosystem changes in the soil}

The species and population of microorganisms in the soil of inoculated and control were determined by spread-plate method ( $\mathrm{Li}$ et al, 2000) and the statistics were showed in Table 1. From the table we can find that after inoculating the number of Bacterium and Actinomycetes all increased and the Fungi decreased. The rate of Actinomycetes to Fungi of inoculated was 2.7, whereas the control was only 0.49. The higher Actinomycetes / Fungi ratio demonstrate the better soil fertility.

\subsubsection{The growth situation and antioxygen enzyme of eggplant seedling}

After 20 days' growth, eggplantseedlings selected in random order were dug out and cleaned with sterile water, plant height, dry weigh, chlorophyll content, antioxidant enzyme such as SOD, CAT and POD were determined. The results showed in Table 2.

From Table 2 we could see clearly that the growth of seedling and the antioxidant enzyme activities in the plant all improved after inoculating the Bacillus subtilis SY1. The Plant height and the dry weight of the seedling increased $56.61 \%$ and $33.55 \%$ respectively. The improvement of chlorophyll content and antioxidant enzyme activities stands for the increase of plant metabolism and stress tolerance. The chlorophyll content is closely related with photosynthesis which provide energy to the plant. SOD is a common enzyme that exists throughout the animal and plant kingdoms, it could remove the superoxide radical. The activity of CAT has a great impact on plant resistance to cold and disease. 
POD is a highly activity enzyme that also common exists in the plant which is close related to therespiration, hotosynthesis and degrade reaction of growth hormone.

\subsubsection{The antifungal effect of Bacillus subtilis SY1}

The antifungal activity of Bacillus subtilis SY1 was tested against the four typical soil-borne pathogen diseases Pythium aphanidermatum, Fusarium oxysporum f.sp.lycopersici, Botrytis cinerea Pers and Alternaria solani on the PDA media. The diameter of fungal inhibition ring demonstrates the inhibitory activity.

From Table 3 and Fig 1 we can see that Bacillus subtilis SY1 has antifungal activity to all these four pathogens to a certain extent, especially D Alternaria solani the diameter of fungal inhibition ring attained $43.6 \mathrm{~mm}$. Alternaria solani is the most common and harmful soil-borne pathogen fungi in agriculture which cause decline of plant yield and quality every year. Bioremediation of inoculating beneficial bacteria Bacillus subtilis SY1 is an effective method to decrease the pathogen fungi amount. The lower quantity and activity of soil-borne pathogen fungi could decrease the disease occurrence so as to guarantee a bumper harvest.

\subsection{American ginseng field experiment}

\subsubsection{The residue of BHC and DDT in the soil and American ginseng}

The separated agent Pseudomonas flurescens WI was expanding cultured and inoculated into the soil of American ginseng planting base. After one year of growth the American ginseng and the soil in the planting base were dug out to be analyzed. American ginsengs selected in random order were dug out and cleaned with sterile water, the BHC and DDT content in them were analysed with gas chromatography/microelectron capture detector. The soil in the American ginseng planting base were collected and analysed with gas chromatography/microelectron capture detector also.

Table 4 showed that the content of BHC and DDT which are two main composition of organic chlorine pesticide in soil decreased $42.50 \%$ and $38.66 \%$ respectively after inoculating of flurescens $W 1$ into soil. From table 5 we can see that the content of BHC and DDT in the American ginseng also decreased $26.08 \%$ and $27.87 \%$ accordingly compared with the control. The less pesticide residue is the quality control of Chinese medicinal materials.

\subsubsection{The growth situation and effective components of American ginseng}

The plant height, leaf area and the total saponins of American ginsengs were determined also. The results are showed in Table 6. Fig 2 is a photo of the inoculated and the control American ginsengs.

From Table 6 we can see that the improvement of the soil after inoculating Pseudomonas flurescens W1 was significantly. The leaf area, plant height and the emergence rate of American ginseng all increased. The detection of total saponins showed that the effective components in the American ginseng increased $18.96 \%$. In Fig 2 we can also found the number of ginseng fibrous roots of inoculated, which plays an important role on nutrient uptake,. were significantly more than the control.

\section{Conclusions}

This two beneficial agents Bacillus subtilis SY1 and Pseudomonas flurescens W1 used in this experiment improved soil physical and chemical properties and fertility, promote soil nutrient sound cycle and accelerate the plant growth.

In the eggplant planting experiment the Bacillus subtilis $S Y 1$ has great antifungal effect on pathogens and the growth and stress resistance of the seedlings in the inoculated soil increased. After inoculating, the plant height, dry weight and chlorophyll content increased $56.61 \%, 33.55 \%$ and $40.1 \%$ respectively. The antioxidant enzymes SOD, CAT and POD improved significantly of $103.2 \%, 127.3 \%$ and $81.5 \%$.

In the American ginseng planting experiment the content of BHC and DDT in the plant and soil decreased $26.08 \%$, $27.87 \%, 42.50 \%$ and $38.66 \%$ after inoculating with the Pseudomonas flurescens W1 in soil. Meanwhile, in inoculated soil the American ginseng grow better and the total saponins in the American ginseng increased $18.96 \%$ accordingly.

\section{References}

D.C. Naseby, J.M. Lynch. (2001). Effect of 2, 4-Diacetylphloroglucinol Producing, Overproducing,and Nonproducing Pseudomonas fluorescens F113 in the Rhizosphere of Pea. Microbial ecology, 42:193-200.

D.C. Naseby, Y. Moënne-LoccozJJ. Powell, et al. (1998). Soil enzyme activities in the rhizosphere of field-grown sugar beet inoculated with the biocontrol agent Pseudomonas fluorescens F113.

Li Hesheng. (2000). Principles and techniques of plant physiological biochemical experiment. Beijing, 164-175.

Marc Ongena, Francéline Duby. (2005). Emmanuel Jourdan et al, Bacillus subtilis M4 decreases plant susceptibility towards fungal pathogens by increasing host resistance associated with differential gene expression. Applied Microbiology and Biotechnology, 67 (5): 692.

Shinji Mizumoto, Makoto Shoda. (2007). Medium optimization of antifungal lipopeptide, iturin A, production by 
Bacillus subtilis in solid-state fermentation by response surface methodology. Applied Microbiology and Biotechnology, 76 (1): 101.

Wang J., Liu J., Chen H., et al. (2007). Characterization of Fusarium graminearum inhibitory lipopeptide from Bacillus subtilis IB. Applied Microbiology and Biotechnology, 376(4): 889.

Wu Jinshui. 2006. Soil microbial biomass--methods and application. Beijing, 3.

ZHANG Wei-qiong; NIE Ming; XIAO Ming. (2007). Advances in biocontrol mechanism of Pseudomonas fluorescens, Journal of Biology, 24(3):9-11.

Table 1. Species and population of microorganisms in inoculated and control soil

\begin{tabular}{ccccc}
\hline Treatment & $\begin{array}{c}\text { Bacterium } \\
\left(\times 10^{7} \mathrm{cfu} \cdot \mathrm{g}^{-1}\right)\end{array}$ & $\begin{array}{c}\text { Actinomycetes } \\
\left(\times 10^{6} \mathrm{cfu} \cdot \mathrm{g}^{-1}\right)\end{array}$ & $\begin{array}{c}\text { Fungi } \\
\left(\times 10^{3} \mathrm{cfu} \cdot \mathrm{g}^{-1}\right)\end{array}$ & $\begin{array}{c}\text { Actinomycetes / } \\
\text { Fungi }\end{array}$ \\
\hline Inoculated & 62.8 & 24.8 & 9.2 & 2.7 \\
Control & 47.6 & 11.6 & 23.6 & 0.49 \\
\hline
\end{tabular}

Table 2. The growth situation and antioxidant enzyme activities of eggplant seedling after 20 days

\begin{tabular}{|c|c|c|c|c|c|c|}
\hline Treatment & $\begin{array}{l}\text { Plant height } \\
\text { (cm) }\end{array}$ & $\begin{array}{c}\text { Dry weight } \\
\text { (mg) }\end{array}$ & $\begin{array}{c}\text { Chlorophyll } \\
\text { Content } \\
\left(\mathrm{mg} \cdot \mathrm{L}^{-1}\right)\end{array}$ & $\operatorname{SOD}\left(\mathrm{U} \cdot \mathrm{g}^{-1}\right)(\mathrm{FW})$ & $\begin{array}{c}\text { CAT } \\
\left(\mathrm{U} \cdot \mathrm{g}^{-1}\right)(\mathrm{FW})\end{array}$ & $\begin{array}{c}\text { POD } \\
\left(\mathrm{U} \cdot \mathrm{g}^{-1}\right)(\mathrm{FW})\end{array}$ \\
\hline Control & $7.912 \pm 0.169$ & $4.717 \pm 0.173$ & $0.536 \pm 0.134$ & $86.210 \pm 0.210$ & $21.075 \pm 0.208$ & $35.883 \pm 0.100$ \\
\hline Inoculated & $12.390 \pm 0.103$ & $6.300 \pm 0.009$ & $0.751 \pm 0.125$ & $175.150 \pm 0.195$ & $47.906 \pm 0.106$ & $65.122 \pm 0.251$ \\
\hline $\begin{array}{c}\text { Increasing } \\
\text { rate }(\%)\end{array}$ & 56.61 & 33.55 & 40.1 & 103.2 & 127.3 & 81.5 \\
\hline
\end{tabular}

Table 3. Inhibitory activities of Bacillus subtilis SY1 to four typical pathogens

$$
\text { Pathogenic bacteria }
$$

Diameter of fungal inhibition ring $(\mathrm{mm})$

$\begin{array}{llr}\text { A } & \text { Pythium aphanidermatum } & 22.4 \\ \text { B } & \text { Fusarium oxysporum f.sp.lycopersici } & 20.2 \\ \text { C } & \text { Botrytis cinerea Pers. } & 16.5 \\ \text { D } & \text { Alternaria solani(Ell.et Mart.) } & 33.6\end{array}$

Table 4. The pesticide residue decreasing effect of BHC and DDT in soil

\begin{tabular}{cccccc}
\hline & BHC in soil & & DDT in soil \\
\hline $\begin{array}{c}\text { Control } \\
(\mathrm{mg} \backslash \mathrm{kg})\end{array}$ & $\begin{array}{c}\text { Inoculated } \\
(\mathrm{mg} \backslash \mathrm{kg})\end{array}$ & $\begin{array}{c}\text { Degradation } \\
\text { rate }(\%)\end{array}$ & $\begin{array}{c}\text { Control } \\
(\mathrm{mg} \backslash \mathrm{kg})\end{array}$ & $\begin{array}{c}\text { Inoculated } \\
(\mathrm{mg} \backslash \mathrm{kg})\end{array}$ & $\begin{array}{c}\text { Degradation } \\
\text { rate }(\%)\end{array}$ \\
\hline $6.204 \pm 0.150$ & $3.567 \pm 0.143$ & 42.50 & $11.946 \pm 0.109$ & $7.328 \pm 0.055$ & 38.66 \\
\hline
\end{tabular}

Table 5. The pesticide residue decreasing effect of BHC and DDT in American ginseng

\begin{tabular}{|c|c|c|c|c|c|}
\hline \multicolumn{3}{|c|}{$\mathrm{BHC}$ in American ginseng } & \multicolumn{3}{|c|}{ DDT in American ginseng } \\
\hline $\begin{array}{l}\text { Control } \\
(\mathrm{mg} \backslash \mathrm{kg})\end{array}$ & $\begin{array}{l}\text { Inoculated } \\
\text { (mg\kg) }\end{array}$ & Degradation rate $(\%)$ & $\begin{array}{l}\text { Control } \\
(\mathrm{mg} \backslash \mathrm{kg})\end{array}$ & $\begin{array}{l}\text { Inoculated } \\
(\mathrm{mg} \backslash \mathrm{kg})\end{array}$ & Degradation rate $(\%)$ \\
\hline $47.439 \pm 0.177$ & $35.065 \pm 0.124$ & 26.08 & $60.915 \pm 0.122$ & $43.937 \pm 0.054$ & 27.87 \\
\hline
\end{tabular}


Table 6. the growth situation and total saponins of the American ginseng

\begin{tabular}{ccccc}
\hline Treatment & Leaf area $(\mathrm{g})$ & Pant height $(\mathrm{mm})$ & Emergence rate & $\begin{array}{c}\text { Total } \\
\text { saponins }(\mathrm{mg})\end{array}$ \\
\hline Control & $61.060 \pm 0.357$ & $12.300 \pm 0.142$ & $71.385 \%$ & $5.8 \%$ \\
\hline Inoculated & $62.735 \pm 0.108$ & $12.526 \pm 0.189$ & $77.586 \%$ & $6.9 \%$ \\
\hline Increasing rate (\%) & 2.67 & 1.6 & 8.5 & 18.96 \\
\hline
\end{tabular}

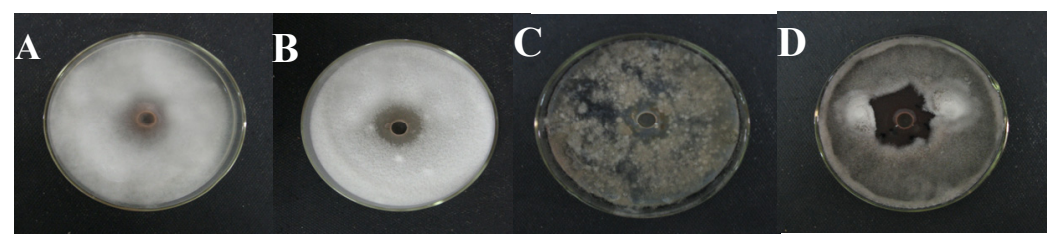

Figure 1. Inhibitory activities figures of Bacillus subtilis SY1 to four typical pathogens

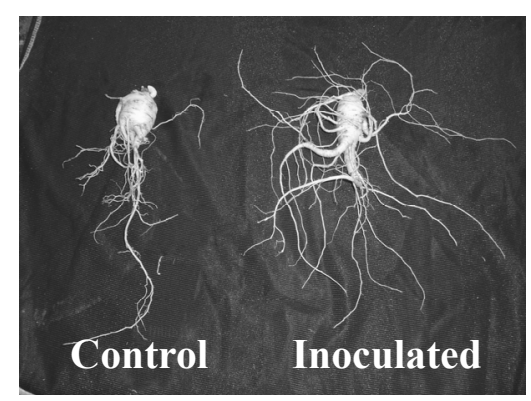

Figure 2. The photo of American ginseng 